\title{
Work Values and Work Performance of Post-90s IT Employees: The Mediating Effect of Organizational Citizenship Behavior
}

\author{
Jieshi Chen ${ }^{1}$, Qiong Zhang ${ }^{2}$ \\ ${ }^{1}$ School of Humanities and Communication, Guangdong University of Finance and Economics, Guangzhou, China \\ ${ }^{2}$ School of Humanities and Communication, Guangdong University of Finance and Economics, Guangzhou, China
}

\begin{abstract}
It aims to explore the effect of post-90s IT employees' work values on their work performance, and the effect of organizational citizenship behavior on the above-mentioned relationships. Optional 354 post-90s IT employees were selected for the questionnaire survey to establish a hypothetical model between post-90s IT employees' work values, organizational citizenship behavior and job performance, and use structural equation models, multiple regression analysis and other statistical methods to conduct hypothesis testing. The empirical research results show that the work values of post-90s IT employees have a significant positive impact on their work performance, and organizational citizenship behavior plays a part of the mediating role in the above effects.
\end{abstract}

\section{INTRODUCTION}

The rapid development of technological revolution and industrial transformation represented by big data, cloud computing, mobile Internet, and 5G technology is profoundly changing the industrial structure and industry pattern of China. As a major member of the Internet revolution, IT companies have become an important engine for economic development, social progress and technological innovation. Born in the 1990s, the post-90s group grew up in the historical period when China's reform and opening up made significant progress, and witnessed the historical process of national economic growth and cultural prosperity. Their special growing environment endowed them with diversified value orientation, strong self-consciousness, distinct personality and fragile ability to withstand pressure [1]. It has become an unavoidable academic focus how the human resource management of the organization adapt to the work values of post-90s employees so as to improve their work performance.

Current research on the intergenerational differences of work values mainly focuses on the groups born before the 1990s, or the intergenerational differences of teachers, migrant workers and other special groups. In this respect, the literature on post-90s IT employees is still relatively few. Therefore, on the basis of previous studies, this paper establishes the relationship model between work values, organizational citizenship behavior and job performance of post-90s IT employees, trying to explain the mechanism of their work values on job performance, and whether organizational citizenship behavior plays an intermediary role in the above mechanisms. The theoretical model was depicted in Fig. 1.

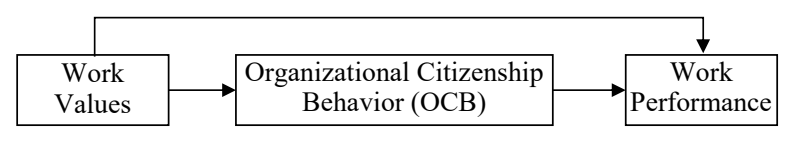

Figure 1. Theoretical model

\section{REVIEW AND HYPOTHESIS}

\subsection{Work Values and Work Performance}

Work values represent the value, importance and degree of expectation of work behaviors and events for individuals [2], as well as the value judgment of individuals on work behaviors and certain results obtained in the work environment [3]. As an important group of the new generation of employees, the post-90s IT employees' work values are different from those of the older generation. They have higher knowledge and culture level, diversified career aspirations and work guidance that ignores authority, and pursue an equal working environment and working status [4] [5].

Work performance refers to the performance of employees at work [6], which is the performance and behavior that individuals can control and contribute to the realization of organizational goals [7], the value and quantity of tasks achieved by employees [8], and all behaviors related to organizational goals that can be measured by the degree of individual contribution to organizational goals [9].

As for the relationship between post-90s IT employees' work values and work performance, some studies have found that employees' work values have an important role in promoting work performance. Employee's work value is a stable belief and evaluation 
system related to work, which guides and influences individual's work behavior and its results. Work values play the role of motivating employees, which can be used to predict employees' work behavior and performance [10], and affect the standard of work behavior and goal selection [11].

$\mathrm{Xu}$ et al. (2016) found in their study of teachers that when work values and working environment conditions are consistent, people will show positive work behaviors, experience job satisfaction, and produce high work performance, while conversely, negative behaviors and job dissatisfaction may result [12]. The study of $\mathrm{Li}$ and Guo (2011) confirmed that there are differences in work values among employees, which have an impact on work behavior and performance [13]. Hou et al. (2018) believed that the work values of the new generation of employees could significantly promote their in-role performance and out-of-role performance [14]. Based on previous studies and the above discussion, this paper proposes the following hypothesis.

Hypothesis 1: The work values of post-90s IT employees have a significant positive impact on their work performance.

\subsection{Work Values and Organizational Citizenship Behavior}

Organizational citizenship behavior (OCB) refers to the behavior that is beneficial to the organization, but has not been clearly or directly confirmed in the formal organizational performance appraisal system [15] [16]. Smith, Morgan, and Near (1983) hold that OCB is neither formally prescribed by the organization, nor can be strengthened or shaped by formal reward and punishment system [17]. Konovsky and Pugh (1994) believe that OCB goes beyond the requirements of duties and tasks, and employees have discretion [18]. Yang et al. (2013) pointed out that OCB refers to the behavior that employees in an organization possess the sense of ownership, which can improve organizational performance [19]. Zhuo et al. (2015) believe that the successful operation of an organization depends not only on the behaviors within the role of employees, but also on the spontaneous behaviors of employees that are beneficial to the organization [20].

Regarding the relationship between work values and OCB, Feather and Rauter (2004) found that there is a significant correlation between work values and OCB [21]. Guo et al. (2006) concluded that collectivism values have a significant impact on OCB [22]. Qin et al. (2007) pointed out that holistic work values have a significant positive impact on OCB [23]. Both Zhang (2011) and Xu et al. (2011) have shown that there is a significant positive correlation between employees' work values and OCB [24] [12]. Based on previous studies and the above discussion, this paper proposes the following hypothesis.

Hypothesis 2: The work values of post-90s IT employees have a significant positive impact on their organizational citizenship behavior.

\subsection{Organizational Citizenship Behavior and Work Performance}

Regarding the relationship between OCB and work performance, Wang (2008) and $\mathrm{Hu}$ (2009) believe that OCB has a significant positive role in promoting work performance [25] [26]. Ke et al. (2006) pointed out that OCB has a positive impact on team work performance [27]. In Wang's (2008) study on young nurses [28], Yang's (2012) study on knowledge workers [29], and Wang's (2015) study on teachers in private colleges and universities [30], they all concluded that OCB can be used as a mediating variable to have a positive impact on work performance. Based on the previous research and the above discussion, this paper proposes the following hypothesis.

Hypothesis 3: The OCB of post-90s IT employees has a significant positive impact on their work performance.

Hypothesis 4: The OCB of post-90s IT employees plays a mediating variable in the relationship between their work values and their work performance.

\section{MethodS}

\subsection{Samples and Procedures}

In this study, data was obtained through questionnaire surveys. The respondents were mainly from IT companies in Guangzhou, Shenzhen and other places. A total of 450 questionnaires were distributed in the survey, of which 390 were from a post-90s sample, with a recovery rate of $86.67 \%$. After checking and screening the questionnaires, 354 valid questionnaires were obtained, with a response rate of $90.77 \%$. In the sample surveyed, men accounted for $61.5 \%$ and women accounted for $38.5 \%$. Unmarried persons accounted for $78.8 \%$ and married persons accounted for $21.2 \%$. Bachelor degree accounted for $63.5 \%$, postgraduate degree or above accounted for $36.5 \%$.

\subsection{Measures}

A seven-point Likert scale ranging from 1 (completely disagree) to 7 (completely agree) was used to measure the four variables involved in the study.

Work values $(\alpha=0.878)$. The work value scale developed by Hong (2012) was adopted in this study, which consists of 14 items in three dimensions, namely attitude tendency, internal demand and professional ethics. According to the situation and object characteristics of this study, 3 items were selected from the three dimensions of the original scale, including 9 items such as "I can give full play to my expertise in work" and "I can engage in work full of change and innovation but not disordered work"[31].

Organizational citizenship behavior $(\alpha=0.826)$. The research adopts the OCB scale of Chinese employees designed by Fan et al. (1997), and selects two items in each of the four dimensions of identity organization, altruistic behavior, due diligence, and maintenance of interpersonal harmony to form a new scale, including "I 
will take the initiative to introduce or promote the company", "I will work hard to maintain the company's image" and other 8 items [32].

Work performance $(\alpha=0.960)$. Based on the work performance scale developed by Van Scotter and Motowidlo (1996), 5 items suitable for this study were selected in combination with Chinese situations and object characteristics, including "I will take the initiative to undertake challenging work", "I will complete the work according to quality standards" and other items [33].
Control variables. Previous studies have suggested that demographic variables may play a role in the workplace. Therefore, this study controls the personal characteristics that may affect the work values, OCB and job performance of the post-90s IT employees, including the gender, marital status, educational background and monthly income. The four variables are defined as categorical variables and coded in the form of dummy variables.

TABLE I. RESULTS OF CONFIRMATORY FACTOR ANALYSIS

\begin{tabular}{ccccccc}
\hline Factor & $\chi^{2}$ & df & $\chi^{2} / \mathbf{d f}$ & RMSEA & TLI & CFI \\
\hline $\begin{array}{c}\text { 3-factor: } \\
\text { WV; OCB; WP }\end{array}$ & 83.870 & 51 & 1.645 & 0.043 & 0.983 & 0.987 \\
$\begin{array}{l}\text { 2-factor: } \\
\text { WV; OCB+WP }\end{array}$ & 254.228 & 53 & 4.797 & 0.104 & 0.899 & 0.919 \\
$\begin{array}{l}\text { 2-factor: } \\
\text { WV+WP; OCB } \\
\text { 2-factor: }\end{array}$ & 198.563 & 53 & 3.746 & 0.088 & 0.927 & 0.941 \\
$\begin{array}{l}\text { WV+OCB; WP } \\
\text { 1-factor: }\end{array}$ & 216.253 & 53 & 4.080 & 0.093 & 0.918 & 0.934 \\
WV+OCB+WP & 361.694 & 54 & 6.698 & 0.127 & 0.848 & 0.876 \\
\hline $\begin{array}{l}\text { Note: WV: Work Values; OCB: Organizational Citizenship Behavior; WP: } \\
\text { Work Performance. }\end{array}$ & & & & & &
\end{tabular}

TABLE II. DESCRIPTIVE STATISTICS AND CORRELATION MATRIX OF CONSTRUCTS

\begin{tabular}{|c|c|c|c|c|c|c|c|c|}
\hline Constructs & 1 & 2 & 3 & 4 & 5 & 6 & 7 & 8 \\
\hline $\begin{array}{l}\text { 1.WV1: } \\
\text { attitude tendency }\end{array}$ & 0.806 & & & & & & & \\
\hline $\begin{array}{l}\text { 2.WV2: } \\
\text { internal demand }\end{array}$ & $0.407 * *$ & 0.896 & & & & & & \\
\hline $\begin{array}{c}\text { 3.WV3: professional } \\
\text { ethics }\end{array}$ & $0.486^{* *}$ & $0.320^{* *}$ & 0.917 & & & & & \\
\hline $\begin{array}{c}\text { 4.OCB1: } \\
\text { identity organization }\end{array}$ & $0.228^{* *}$ & $0.172 * *$ & $0.138^{* *}$ & 0.872 & & & & \\
\hline $\begin{array}{l}\text { 5.OCB2: } \\
\text { altruistic behavior }\end{array}$ & $0.116^{*}$ & $0.222^{* *}$ & 0.039 & $0.389 * *$ & 0.850 & & & \\
\hline $\begin{array}{l}\text { 6.OCB3: } \\
\text { due diligence }\end{array}$ & $0.127^{*}$ & $0.219^{* *}$ & 0.088 & $0.332 * *$ & $0.362 * *$ & 0.893 & & \\
\hline $\begin{array}{l}\text { 7.OCB4: } \\
\text { maintaining harmony }\end{array}$ & $0.120^{*}$ & $0.146^{* *}$ & $0.147^{* *}$ & $0.374 * *$ & $0.301^{* *}$ & $0.322^{* *}$ & 0.891 & \\
\hline $\begin{array}{c}\text { 8.WP: } \\
\text { work performance }\end{array}$ & $0.416^{* *}$ & $0.303 * *$ & $0.298 * *$ & $0.164 * *$ & $0.192 * *$ & $0.233^{* *}$ & $0.244 * *$ & 0.910 \\
\hline Means & 4.442 & 4.310 & 4.358 & 4.518 & 4.500 & 4.596 & 4.517 & 4.455 \\
\hline SD & 1.142 & 1.332 & 1.332 & 1.428 & 1.444 & 1.438 & 1.423 & 1.529 \\
\hline
\end{tabular}

Note1: ${ }^{*} \mathrm{p}<0.050,{ }^{* *} \mathrm{p}<0.010 . \mathrm{N}=354$

Note2: The value on the diagonal is the square root of AVE.

\section{Results}

\subsection{Reliability and Validity Test}

In terms of reliability, Cronbach's $\alpha$ was used in this study to estimate the reliability of each variable. The Cronbach's $\alpha$ of work values, OCB and work performance are 0.878 , 0.826 and 0.960 , respectively, which are all greater than 0.7 , indicating a good internal consistency of the scale. In terms of content validity, because this study refers to the maturity scale of previous scholars, it has a reliable content validity. In terms of discriminant validity, the average variance extracted (AVE) was used in this study (see Table 2), and the results showed that the square root 
of AVE was greater than the correlation coefficient between variables. Therefore, there is a good discriminant validity between variables. In addition, confirmatory factor analysis (CFA) was used in this study to further test the discriminant validity among variables (see Table 1). The 3-factor model $\left(\chi^{2}=83.870 ; \mathrm{df}=51\right.$; RMSEA $=0.043$; $\mathrm{CFI}=0.987$; $\mathrm{TLI}=0.983$ ) has better fitting effect than other nested models, and has a good matching index, which meant that the discriminant validity between variables was further verified.

\subsection{Descriptive Statistics of Variables}

The mean, standard deviation, correlation coefficient and the square root of AVE of the variables are shown in Table 2. The results show that all aspects of work values and OCB are significantly related to work performance, indicating that work values and OCB play an important role in work performance; In terms of the relationship between work values and OCB, except for the professional ethics of work values and the altruistic behavior and due diligence of OCB, there are significant correlations between other aspects, which shows that work values have an impact on OCB. The above results initially support hypothesis 1,2 and 3 .

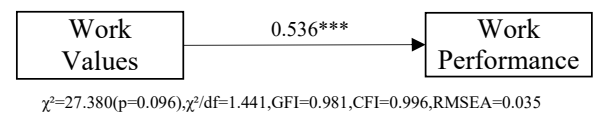

Figure 2. Direct impact model (model 1)

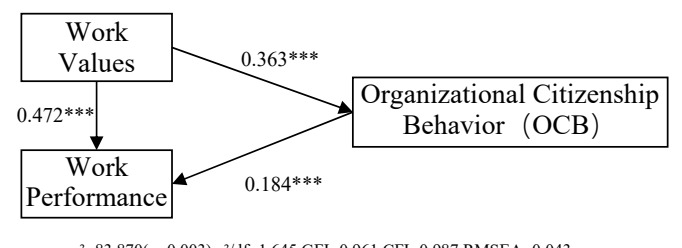

Figure 3. Mediating variable model (model 2)

\subsection{Hypothesis Test Results}

In this paper, AMOS22.0 is used as an analysis tool to detect the role of $\mathrm{OCB}$ as a mediator variable by constructing a competition model (i.e., parameter estimation and significance difference assessment for two substantive models). We first constructed a direct impact model (model 1, see figure 2) to verify the direct impact of work values on work performance. The results of model 1 show that when there is no mediating effect of OCB, work values have a significant positive effect on work performance $(\beta=0.472, \mathrm{p}<0.001)$, and hypothesis 1 is supported.

Then we construct a mediation variable model (model 2 , see figure 3 ) to verify the correlation between work values, OCB and work performance. The results of model 2 show that the work values of post-90s IT employees have a significant positive impact on their work performance $(\beta=0.472, \quad \mathrm{p}<0.001)$. Hypothesis 1 is supported. The work values of post-90s IT employees have a significant positive impact on their OCB. $(\beta=0.363$, $\mathrm{p}<0.001)$. Hypothesis 2 was supported. The OCB of post90s IT employees has a significant positive impact on their work performance. $(\beta=0.184, \mathrm{p}<0.001)$. Hypothesis 3 is supported.

Comparing the above model 1 and model 2, we find that work values not only have a direct positive impact on work performance (direct impact effect is 0.536), but can also have an indirect positive impact on work performance through OCB (indirect impact effect: $0.363 \times 0.184=0.066$ ). Therefore, the OCB of post-90s IT employees plays a part of the mediating role in the relationship between their work values and their work performance, and hypothesis 4 is supported.

TABLE III. RESULTS OF REGRESSION ANALYSIS OF MEDIATING EFFECT

\begin{tabular}{|c|c|c|c|c|c|}
\hline \multirow{2}{*}{ Variables } & \multicolumn{2}{|c|}{ Organizational citizenship behavior } & \multicolumn{3}{|c|}{$\begin{array}{c}\text { Work } \\
\text { performance }\end{array}$} \\
\hline & model 1 & model 2 & $\begin{array}{c}\text { model } \\
\mathbf{3} \\
\end{array}$ & model 4 & model 5 \\
\hline \multicolumn{6}{|c|}{ Control variables } \\
\hline Gender & 0.063 & 0.059 & 0.000 & -0.007 & -0.018 \\
\hline Marriage & 0.086 & 0.085 & -0.041 & -0.042 & -0.059 \\
\hline Education & 0.033 & 0.014 & 0.088 & 0.057 & 0.054 \\
\hline Income & 0.040 & 0.044 & $0.122 *$ & $0.129 *$ & $0.121 *$ \\
\hline \multicolumn{6}{|c|}{ Independent variables } \\
\hline Work values & & $0.267 * * *$ & & $0.432 * * *$ & $0.381 * * *$ \\
\hline \multicolumn{6}{|c|}{ Mediating variables } \\
\hline $\begin{array}{c}\text { Organizational citiz } \\
\text { behavior }\end{array}$ & & & & & $0.191 * * *$ \\
\hline $\mathrm{R}^{2}$ & 0.014 & 0.084 & 0.020 & 0.204 & 0.238 \\
\hline$\Delta \mathrm{R}^{2}$ & 0.014 & 0.070 & 0.020 & 0.184 & 0.033 \\
\hline $\mathrm{F}$ & 0.816 & $26.619 * * *$ & 1.188 & $80.173 * * *$ & $15.091 * * *$ \\
\hline
\end{tabular}




\subsection{Robustness Test}

In this study, the mediation effect test model proposed by Baron et al. (1986) was used to test the robustness of the research results. As showed in table 3, we first verified that work values have a significant positive impact on work performance (model $4, \beta=0.432, p<0.001$ ), and then verified that work values have a significant positive impact on OCB (model 2, $\beta=0.267, \mathrm{p}<0.001$ ). Then the work values and OCB were simultaneously regressed to work performance. The results showed that the regression coefficient of OCB was significant (model 5, $\beta=0.191$, $\mathrm{p}<0.001$ ), and the coefficient of work values was significantly reduced compared with model 4, and reached Significance level (model 5, $\beta=0.381, \mathrm{p}<0.001$ ). It can be seen that the OCB of post-90s IT employees plays a part of the mediating effect between work values and work performance. The results of the mediation effect model test and the structural equation model test are highly consistent, which shows that the research results have good robustness.

\section{Conclusion AND Discussion}

\subsection{Research Conclusions}

Based on 354 samples from IT companies, this study conducts an empirical study on the relationship between post-90s IT employees' work values, OCB and work performance, and constructs a theoretical model of "work values - organizational citizenship behavior - work performance" of post-90s IT employees in the Chinese context. Research conclusions show that the work values of post-90s IT employees have a positive effect on OCB and work performance, and OCB has a partial mediating effect on the relationship between work values and work performance of post-90s IT employees. Under the guidance of their work values which are conducive to the realization of organizational goals, post-90s IT employees can bring about better OCB, so as to achieve its positive impact on work performance.

\subsection{Management Implications}

The research results enrich the literature on the work values of post-90s IT employees, and provide a certain reference for the research on the intergenerational theory of work values and the research on industry environment differences, as well as the organization and management practices of post-90s employees. First of all, the organization should recognize the intergenerational difference of employees' work values, understand the specific status of the work values of the post-90s as a special group through research, meet the organizational needs of post-90s employees in a targeted way, and take effective incentive measures to encourage them to show better OCB. Secondly, organizations should recognize that there are differences in the work values of employees in the industry environment. As a knowledge-intensive organization, IT companies should do a good job of measuring the work values of post-90s employees in important links such as human resource planning, talent introduction, ability training and performance appraisal, and rationalize the staffing of different generations to improve the efficiency of human resource management. Finally, IT companies need to pay attention to shaping the work values of post-90s. It can rationally guide employees to build work values that are conducive to the development of the company through the introduction of corporate culture and personal value cultivation, so that employees can increase work investment and improve work performance, thereby promoting the realization of organizational goals.

\subsection{Research Limitations and Future Research Directions}

Inevitably there are some limitations of this research: First, it takes a certain time to shape work values. Therefore, its influence on OCB and the mediating role of OCB has a certain time span, although this study method used by several times as much as possible to collect and from multiple sources to reduce common method biases, but is not really a longitudinal study. In the future, we can try to track the relationship between causal variables and add case studies and situational experimental studies on the basis of empirical research to enhance the reliability of research results. Secondly, the research data in this article mainly come from first-tier cities such as Guangzhou and Shenzhen. The research results may be affected by regional factors. Future research can further broaden the data sources to increase the representativeness of the research conclusions. Finally, the development of the different enterprise scale, enterprise culture, leadership style and other factors may affect the relationship between post-90s IT employees' work values, OCB and work performance. This study failed to take the above variables into consideration. Future research can Incorporate the above factors into the research model as a moderating variable or a mediating variable, and construct a moderated mediation model or multiple mediation model to more comprehensively examine the impact of work values on work performance.

\section{REFERENCES}

1. Li Xiyuan, Li Hongjin. The construction of post-90s employee management system-Based on the perspective of organizational socialization strategy[J]. China Human Resources Development, 2012(12): 23-27.

2. Knoop R. Achievement of work values and participative decision-making[J]. Psychological reports, 1991, 68(3): 775-781.

3. Elizur D. Facets of work values: A structural analysis of work outcomes[J]. Journal of applied psychology, 1984, 69(3): 379.

4. Chen Hong, Yan Shifu. The impact of new generation employees' work values and 
psychological empowerment on job performance: An Empirical Study Based on knowledge-based enterprises $[\mathrm{J}]$. Science and technology and economics, 2014,27 (02): 71-75.

5. Burkus D. Developing the next generation of leaders: How to engage millennials in the workplace[J]. Leadership Advance Online, 2010, 19: 1-6.

6. Huang Yingzhong, Cao Guoxiong, Huang Tongzhen.Human Resource Management, Taipei: Huatai Book Co. [J].1997.

7. Zhao Hongdan. Is the twisted melon sweet or not?- The impact of compulsory organizational citizenship behavior perceived by employees on work performance[J]. Economics and Management Research, 2014(11): 71-79.

8. Schemerhorn J R, Hunt J G, Osborn R N. Fundamentos de comportamento organizacional, 2. ${ }^{\mathrm{a}}$ edição[J]. 1999.

9. Borman W C, Motowidlo S M. Expanding the criterion domain to include elements of contextual performance[J]. 1993.

10. Adkins C L, Naumann S E. Situational constraints on the achievement-performance relationship: A service sector study[J]. Journal of Organizational Behavior: The International Journal of Industrial, Occupational and Organizational Psychology and Behavior, 2001, 22(4): 453-465.

11. Lyons S T, Duxbury L E, Higgins C A. A comparison of the values and commitment of private sector, public sector, and parapublic sector employees[J]. Public administration review, 2006, 66(4): 605-618.

12. Xu Xingchun, Zhang Dajun. An Empirical Study on Teachers' Work Values and Their Influencing Factors [J]. Journal of Sichuan Normal University (Social Science Edition), 2011, 38(03): 113-118.

13. Li Weining, Guo Yuejuan. Research on the relationship between work values and work performance of employees in communication enterprises[J]. Statistics and Decision, 2011 (04): 185-188.

14. Hou Xuanfang, Lu Fucai. The influence of the new generation of work values and intrinsic motivation on work performance-the moderating effect of organizational culture $[\mathrm{J}]$. Management Review, 2018, 30(04): 157-168.

15. Organ D W, Ryan K. A meta-analytic review of attitudinal and dispositional predictors of organizational citizenship behavior[J]. Personnel psychology, 1995, 48(4): 775-802.

16. Podsakoff P M, MacKenzie S B, Paine J B, et al. Organizational citizenship behaviors: A critical review of the theoretical and empirical literature and suggestions for future research $[\mathrm{J}]$. Journal of management, 2000, 26(3): 513-563.

17. Smith C, Organ D W, Near J P. Organizational citizenship behavior: Its nature and antecedents[J]. Journal of applied psychology, 1983, 68(4): 653.
18. Konovsky M A, Pugh S D. Citizenship behavior and social exchange $[\mathrm{J}]$. Academy of management journal, 1994, 37(3): 656-669.

19. Yang Baiyin, Lian Xin, Ma Yueting. The structure and measurement of the organizational innovation atmosphere in Chinese enterprises[J]. Science of Science and Management of Science and Technology, 2013, 34(08): 43-55.

20. Zhuo Zhengqin, Guo Hongwei. The relationship between organizational justice and organizational citizenship behavior: job satisfaction as an intermediary variable[J]. Management Information Computing, 2015, 4(1): 263-276.

21. Feather N T, Rauter K A. Organizational citizenship behaviours in relation to job status, job insecurity, organizational commitment and identification, job satisfaction and work values[J]. Journal of occupational and organizational psychology, 2004, 77(1): 81-94.

22. Guo Xiaowei. An analysis of the predictive and moderating effects of two values on organizational citizenship behavior [J]. Journal of Nanjing Normal University (SOCIAL SCIENCE EDITION), 2006 (02): 110-115.

23. Qin Qiwen, Yao Jingzhao, Li genqiang. Research on the relationship between employees' work values and organizational citizenship behavior [J]. Psychological science, 2007 (04): 958-960.

24. Zhang aijuan. Research on the influence of work values on employees' organizational citizenship behavior [D]. Hangzhou University of Electronic Science and technology, 2011.

25. Wang Qin. Research on the relationship among organizational change cognition, organizational citizenship behavior and job performance [D]. Fudan University, 2008.

26. $\mathrm{Hu}$ Xiaowen. Research on the relationship between organizational citizenship behavior and job performance of hotel employees [D]. Xiamen University, 2009.

27. kelifei, Huang Yuanzhi, Ke Lijia. The relationship among team cohesion, organizational citizenship behavior and job performance: An Empirical Study Based on service enterprises [J]. Research on financial issues, 2007 (02): 93-97.

28. Wang Ping. Research on the relationship between job satisfaction, organizational citizenship behavior and personal work performance of young nurses [D]. Hebei Medical University, 2008.

29. Yang Xingxing. Research on the relationship among well-being, organizational citizenship behavior and job performance of knowledge workers [D]. Zhejiang University of Finance and economics, 2012.

30. Wang Xiaoli. The relationship between job wellbeing and job performance of private university teachers: the moderating effect of organizational commitment and the mediating effect of 
organizational citizenship behavior [J]. Higher education forum, 2015 (09): 92-95.

31. Hong Kesen. Research on the mechanism of work values and organizational identity of new generation employees on their output [D]. Wuhan University, 2012.

32. fan Jingli, Zheng Bolong. Self modesty bias in Chinese self-evaluation performance appraisal: topic meaning, modest value and self-esteem [J]. Chinese Journal of psychology, 1997, 39 (2): 103.
33. Van Scotter J R, Motowidlo S J. Interpersonal facilitation and job dedication as separate facets of contextual performance[J]. Journal of applied psychology, 1996, 81(5): 525.

34. [34] Baron R M, Kenny D A. The moderatormediator variable distinction in social psychological research: Conceptual, strategic, and statistical considerations[J]. Journal of personality and social psychology, 1986, 51(6): 1173. 